\title{
EVOLUCIÓN SOCIO-POLÍTICA DE CÁSTULO: SOCIEDAD DE JEFATURA
}

\author{
MARÍA PAZ GARCÍA-GELABERT \\ Universidad Complutense de Madrid
}

\begin{abstract}
El proceso socio-político en la ciudad de Cástulo y su entorno, perteneciente a la Oretania en la Alta Andalucía, se desarrolló, a lo largo de los siglos, desde una sociedad igualitaria a una sociedad de clases que pudo desembocar en una sociedad de jefatura. Esta transformación fue dinamizada por el creciente auge del comercio de los metales que los castulonenses cambiaban a los mercaderes procedentes de las factorías costeras por productos exóticos, generalmente indicadores de prestigio social para quienes los adquirían.

El control de los excedentes y la redistribución de los productos es el principal ingrediente para la formación de una sociedad de jefatura, hecho que parece ocurrió en Cástulo. Dicho tipo de organización política tiene, según Service $(1971,222)$ la estructura adecuada para extender ampliamente el sistema de intercambios, y está cumplidamente documentado en la zona que se trata.
\end{abstract}

The social and politic development of Castulo and its environs goes from a egalitarian society to a class-society, and perhaps to a chief-society. This change was stimulated by the trade between the indigenous and foreign merchants, which brought exotic and prestigious products in exchante to metal. This trade must have important for the social process to a chief-society.

El tema de la evolución socio-política y económica de los pueblos primitivos prehistóricos y protohistóricos afecta de forma directa al arqueólogo, quien, a través de los datos recuperados en campañas de excavación y de los ejemplos extraídos de los análisis etnográficos y etnohistóricos, así como del análisis de los textos, debe, desde esta perspectiva, interpretar los materiales de que disponga.

Es esencial, desde el doble aspecto humano y social, incidir en el problema del cambio de una sociedad igualitaria a una sociedad de clases y estado; en el estudio de las alteraciones que propiciaron el que una sociedad igualitaria se permute en una de clases. En esta serie de evoluciones a través del tiempo están involucradas la organización socio- política, las creencias, la economía, la tecnología, la utilización de los recursos del entorno, es decir, todos los aspectos referentes a los valores inherentes al pueblo/s o sociedad/es a que el estudio se refiera.

En el ritmo de cambio evolutivo existe una sociedad intermedia entre la sociedad igualitaria y la formación del Estado - estadio este último que no llegaron a alcanzar los pueblos protohistóricos peninsulares no sólo si nos atenemos a lo que de ellos escribe Estrabón $(3,4,5)$, concretamente de los íberos, en el sentido de que su carácter orgulloso, versátil y complejo les impidió unir sus fuerzas en una confederación potente, sino también a los resultados que sobre este tema están alcanzando las actua- 
les investigaciones. Pudo haber confederaciones, pero no extensas, que lograran incorporar a diferentes tribus de una región o a parte de ellas. De éstas pudieron ser aquellas a las que se refieren $\mathrm{Li}$ vio $(28,10 ; 33,21,6)$, a cuyo frente se encontraba el que denomina rey Kulchas o Colchas, y Diodoro $(25,10-12)$ cuando cita la batalla entre Asdrúbal y el rey Orisson, de doce ciudades oretanas. Por otro lado, creo acertada la hipótesis de C. González Wágner, $(1983,31)$, sobre que ningún jefe local, tras la ruptura de la confederación tartésica, estuvo en condiciones de controlar un territorio mucho más amplio que aquel que tradicionalmente pertenecía a su propio clan o tribu. La formación de confederaciones parece ser de carácter excepcional. La sociedad a la que me refiero es la denominada de jefatura (chiefdom), o de rango, según los diferentes autores que tratan la misma. Es en ella en donde hipotéticamente - aún no se ha profundizado lo suficiente en los estudios como para asegurarlo sin margen de error - quedó anclado el desarrollo político ibero. Concretamente, en Cástulo no llegó a derivar a la formación de Estado. Eso sí puede afirmarse con certeza actualmente. Queda en reserva el que futuras investigaciones arqueológicas en el área ibérica de la ciudad, que se están demorando excesivamente, proporcionen datos que rebatan la afirmación presente.

Hay un hecho incontrovertible y claramente constatable en los estudios de las sociedades de jefatura: hasta el momento, el límite entre sociedad igualitaria y de jefatura y entre ésta y Estado es muy difuso en el proceso de las civilizaciones y es incuestionable que aún siguen vigentes las palabras de R. L. Carneiro $(1981 ; 37)$, cuando escribe que: «desde luego, la principal conclusión a que llegamos en la conferencia que inspiró este volumen es que aún conocemos muy poco sobre las jefaturas».

Conviene, antes de abordar la relación sociedad de jefatura-Cástulo, realizar una brevísima síntesis de los estudios pioneros en torno a las sociedades de jefatura.

El concepto de sociedad de jefatura fue utilizado ya por J. H. Steward en el cuarto volumen de Handbook of South American Indians (STEWARD, ed. 1948), refiriéndose a los señoríos del área Circum-Caribe, y por H. Trimborn (1949) en su estudio del valle del Cauca. Del término (chiefdom), Kalervo Oberg $(1955,484)$ ofrece la siguiente definición: «unidades tribales pertenecientes a este tipo son jefaturas territoriales multialdeanas gober- nadas por un jefe supremo bajo cuyo control hay distritos y aldeas gobernadas por una jerarquía de jefes subordinados»).

El término acuñado por este investigador es aceptado poco más tarde por J. H. Steward-L. C. Faron (1959) y por E. R. Service $(1962,1971)$, uno de los científicos, éste, que más han profundizado en el estudio evolutivo de las sociedades primitivas. Según el mismo, «una jefatura ocupa un nivel de integración social que trasciende la sociedad tribal en dos aspectos importantes: en primer lugar, una jefatura es usualmente una sociedad más densa que lo es una tribu, una ventaja que se hace posible por una productividad mayor. Pero en segundo lugar y más indicativo del nivel evolutivo, la sociedad es también más compleja y más organizada, siendo particularmente distinguible de las tribus por la presencia de centros que coordinan actividades económicas, sociales y religiosas» (SERVICE, 1971, 133).

A partir de la publicación del libro de Service en 1962, se han multiplicado los estudios individuales y colectivos, tendentes a clarificar la evolución de los pueblos, de su civilización y cultura, y a tratar de elaborar una metodología y analizar procesos de comportamiento.

Destacan entre los estudiosos, sin que sea nuestro propósito hacer una relación completa: Sahlins y Service, eds. (1960); Lenski (1966); R. M. Adams (1966); Fried (1967); Bell-Edward-Wagner, eds. (1969); R. N. Adams (1975); Earle y Ericson, eds. (1977); Claessen y Skalnik, eds. (1978); Cohen y Service (1978); Friedman y Rowlans, eds. (1978); Korn (1978); Redman (1978); Haas (1979), y Jones y Kautz, eds. (1981). En 1985, el XLV Congreso Internacional de Americanistas, celebrado en Bogotá y organizado por Robert D. Drennan y Carlos Castaño Uribe, versó precisamente sobre la investigación arqueológica y los cacicazgos en América, con aportaciones tan importantes como las de Kent G. Linghtfoot, Christopher S. Peebles, Joanne Rappapor y Charles S. Spencer, entre otros.

A los efectos de esta exposición, se va a tomar el ejemplo de la ciudad de Cástulo, a la que he aludido arriba, que puede ser aplicable no solamente al pueblo oretano al que pertenece, sino a los restantes coetáneos.

Cástulo cuenta con un emplazamiento con perfecto dominio estratégico, abundancia de agua, fértiles tierras, veneros de almagra, vetas de arcilla, proximidad de los yacimientos mineros y fáciles comunicaciones terrestres y fluviales. Estos hechos 
propiciaron su configuración como uno de los principales núcleos de distribución y aprovisionamiento de productos materiales de la Alta Andalucía, lo que sería, a su vez, motivo de constantes e importantes procesos de transculturación.

Una secuencia tan prolongada como la que se encuentra en Cástulo — se puede seguir el poblamiento a partir de la etapa del Bronce Final, concretamente desde la primera mitad del siglo VIII a. C.- plantea transformaciones culturales, sociopolíticas y económicas múltiples: cambio de una sociedad igualitaria, banda o tribu, de agricultores y ganaderos autosuficientes, a una sociedad estratificada de productores de excedentes, dedicados éstos al mantenimiento del elemento humano ocupado en menesteres diferentes, alfareros, metalúrgicos, albañiles, tejedores, etc., especialistas desligados de la producción directa de alimentos y cuyo papel estaría relacionado con la centralización y redistribución de excedentes comunales.

No se puede dudar que el principal factor económico que aceleró el proceso de enriquecimiento de la sociedad castulonense fue la explotación de las minas y el comercio del mineral, que se puede remontar a épocas alejadas en el tiempo. A partir de fines del siglo VIII a. C., se halla que la zona de Cástulo comienza a diversificar las bases de su economía, iniciando el camino hacia formas de vida más lucrativas, basadas en recursos del subsuelo. Ello no creo ocurra como consecuencia de un largo proceso de desarrollo local, al menos en esta etapa primera protohistórica, sino como resultado principalmente de la intrusión en el área de grupos humanos portadores de la técnica metalúrgica, procedente de la zona onubense.

Este ritmo de cambio, cuyo embrión radica en la última época del Bronce Final, cristaliza en la cultura y pueblo oretanos, que en el período de tiempo existente entre fines del siglo $\mathrm{V}$ y mediados del siglo IV a. C. alcanza su máximo esplendor potenciado por la explotación minera. Diodoro $(\mathrm{V}, 36$ 38 ), cuando trata de las minas de Hipania, documenta su explotación por los iberos: «...los iberos comprendieron las ventajas de la plata y pusieron en explotación minas de importancia. Por lo cual obtuvieron plata estupenda y, por decirlo así, abundantísima, que les produjo ganancias espléndidas». Cástulo, situado en el centro de una región tradicionalmente minera, productora de hierro, cobre, plomo, anglesita y plata, extremo al que hacen referencia las fuentes clásicas (ESTRABÓN 3, 2, 8-
11, 14; MELA II, 86; PLINIO NH III, 30; DIODORO, V, 36-38, entre otros), se llegó a convertir en uno de los centros productores de plata más importantes de la Hispania antigua. Este hecho dio lugar a un ritmo de vida de activos intercambios comerciales con los mercaderes fenicio-púnicos y griegos, en determinados casos al control militar de las zonas claves de paso y de las minas, a interrelaciones culturales, trasvases de ideas, creencias y arte, que se reflejan, aunque si bien de forma parcial, lo suficientemente ilustrativa, en el poblado y en las necrópolis.

Oretania fue un lugar de cruce entre la Meseta, la Alta Andalucía y el Levante español. Presenta una estrecha relación con los puntos de mayor importancia comercial de las costas de Levante y Andalucía (LÓPEZ DOMECH 1984, 139). Cástulo se encuentra en la depresión periférica que se extiende desde Linares hasta Alcaraz. Es, pues, una vía de paso para ir desde la depresión del Gualdalquivir al Levante. Constituye este corredor natural una vía de comunicaciones perfecta, usada como camino hasta el siglo XVIII para relacionar la Mancha y Andalucía (corredor de Levante o puertos de Montizón). Asimismo, las serranías subbéticas, aunque muy abruptas, presentan grandes facilidades para la comunicación con la costa a través de Granada (HIGUERAS 1961, 20). En las serranías subbéticas se abren profundos entrantes: el surco por el que se abre paso el Guadiana Menor, las extensas depresiones de la Hoya de Baza, la Hoya de Guadix y las tierras llanas de Granada. Los valles de las serranías subbéticas, orientados de Norte a Sur, enlazarían Cástulo con el Sur (Granada, Almería, por Baza), formando unos corredores muy transitados desde la época final de la Edad del Bronce. Las serranías subbéticas presentan en su extremo oriental un gran conjunto orográfico, constituido por las sierras de la Sagra, Cazorla y Segura, uno de los principales núcleos hidrográficos españoles, nacimiento de los ríos Guadalquivir, Guadiana Menor, Segura y Guadalentín. El curso de estos ríos ha ido conformando una serie de rutas conocidas desde la Edad del Bronce. El contacto, pues, entre las diversas zonas que componen la Alta Andalucía y el paso de las comarcas limítrofes, a pesar de lo accidentado del terreno, es fácil, ya que todas las zonas tienen una salida natural hacia el Guadalquivir, contando, por otra parte, con pasos trazados por los numerosos cursos de la red fluvial existente. A este respecto, es importante conocer la descripción de, 
al menos, parte de las vías de comunicación, que a propósito del establecimiento de patrones de asentamiento en las campiñas del Alto Guadalquivir han realizado A. Ruiz y M. Molinos (1984, 189-190). En su trabajo tratan la vía romana que unía Córdoba con Cástulo, así como de la que cita Estrabón (3, $4,9)$, que pasa por Cástulo y Obulco, vía muy antigua. Indican, asimismo, que hacia el Sur el piedemonte fue otra antigua ruta que conectaba la zona costera de Andalucía y las altiplanicies granadinas con el valle. Esta ruta, en razón de estar muy entroncada a la sierra, según los mismos autores, se halla en relación directa con las de ganado que bajaban hasta el valle en las épocas frías y fue utilizada desde la Edad del Cobre, durante el Bronce pleno y en época romana (RUIZ, NOCETE, SÁNCHEZ, 1986). Son también analizadas las vías verticales que conectan el Prebético de Jaén y la Alta Andalucía con el valle; de ellas destacan A. Ruiz y M. Molines dos (1984, 190): de un lado, la del Salado de los Villares, que conecta con la baja campiña algo más al Este de Arjona, el piedemonte de Martos y la ruta que desde el Sureste de la provincia conecta con el mundo de la Hoya de Granada; y en la parte más oriental, las del grupo del río Torres, que en un tramo muy corto sale al vado del Guadalquivir en Puente del Obispo y tiene muy fácil el acceso a la zona minera de Cástulo por la depresión Linares-Baza.

Cástulo contaba, pues, con dos factores importantes para acelerar su desarrollo: producción minera con excelente materia prima - plata-, intercambiable, y situación favorable para controlar el tránsito de mercancías por los caminos. Además, el medio ambiente en el que se halla siempre fue propicio para el incremento, conforme las técnicas se hacían más elaboradas, de la agricultura y la ganadería, pilares básicos de ulteriores logros económicos. El patrón de poblamiento que rodea la ciudad parece haberse caracterizado por la existencia de aldeas nucleadas dependientes de aquélla y labranzas dispersas. La presencia de un alto índice de concentración en los asentamientos en torno a Cástulo, muchos de los cuales se hallan detectados, más no excavados, indica el extremo expuesto en el párrafo anterior.

El sistema económico de los pueblos antiguos se desarrolla a partir del sistema de intercambio (POLANYI 1976). El control del mercado y de las vías de comunicación beneficia el desarrollo económico, cultural y político del pueblo que ejercía el mismo. Y el desarrollo de los mercados implicará un aumento de la infraestructura viaria y el reforzamiento de los entes políticos a cuyo cargo probablemente se encontraría la dirección del sistema mercantil. Además, en el aspecto político, la organización y gestión del mercado necesariamente llevan aparejada la figura de un jefe de claro prestigio social que controle los excedentes, consistentes en materias primas, en la zona estudiada, minerales esencialmente, además de productos vegetales y animales para el abastecimiento de los mercaderes llegados del exterior (que adquirirían para su manuntención, conjuntamente con los metales para su lucro), y para aquellos miembros del poblado dedicados a la producción de los bienes comerciables. Esta jerarquía se refleja justamente en los objetos materiales, signos externos de poder y status, depositados, sobre todo, en las tumbas erigidas en memoria de los grandes personajes, y de las que me ocuparé más adelante. Los vasos áticos, objetos exóticos, como marfiles, vidrios, telas, maderas, etc., llegados de Oriente, fueron tanto más apreciados cuanto que los iberos no tenían acceso directo a ellos. No fue el ibero un pueblo que se distinguiera por sus marinos, antes bien, según parece, vivía de espaldas al mar. De similar opinión es J. Alvar (1980, 1981, 1986), quien, además de afirmar que las poblaciones del mediodía peninsular vivieron de espaldas al mar, indica que las relaciones comerciales marítimas eran competencia exclusiva de los mercaderes orientales. Es importante el testimonio que aporta Livio $(34,9)$ sobre este extremo: «los españoles, ignorantes de la navegación, se alegraban con el comercio de aquéllos (griegos de Ampurias) y deseaban comprar las mercancías extranjeras que las naves llevaban y vendían productos de sus campos».

Por lo que respecta al carácter del comercio en sí mismo, para que pudiera funcionar a través de grandes extensiones de terreno, a veces de pueblos enemigos, otras veces abocados a ser atacados por las bandas celtíberas y lusitanas impelidas fuera de sus territorios por el hambre que llevaba consigo la carencia de tierras de cultivo, debía regirse por unas normas muy determinadas y concretas, las cuales investirían a los comerciantes de un cierto carácter invulnerable. Leyes tácitas o tratadas, puesto que de otra manera el comercio hubiera resultado impracticable. Así, aunque tales leyes no siempre llegarían a cumplirse, sí lo serían en un número de ocasiones muy considerable, puesto que en caso contrario no 
se hubiesen encontrado, al menos en tierras del interior, productos exóticos.

Los mercaderes transitarían por las tierras hispanas protegidos por esa especie de tratados (al hablar de mercaderes me refiero a los que traficaban con productos procedentes del comercio exterior, para las mercancías locales, de pueblo a pueblo, las normas serían más simples), no creo que por escolta militar facilitada por los grupos con los que tenían concertados sus trueques, aunque existe la posibilidad, no descartable, de que los mercaderes contratasen en su tierra de origen una tropa de protección, por la que serían acompañados.

Si los acuerdos referentes al comercio existieron, como parece probable, están indicando que el mismo era una actividad que se desarrollaba entre los pueblos iberos o los de la Meseta, con respecto a los mercaderes orientales, desde las clases dirigentes, las únicas con autoridad, autonomía de acción y elementos de juicio suficientes como para concertar esos tratados. Sería, pues, una actividad canalizada por la oligarquía y principalmente para su beneficio, aunque cierta parte de los mismos revirtiera al bien común, no individual, sino comunal.

Esta argumentación coincide con la opinión de López Domech $(1984,141)$, que cita a Finley (1974), acerca de que la actividad comercial tiene en el Mediterráneo occidental un sentido administrativo y político, al menos antes de la expansión bárquida en el siglo III a. C., lo que haría necesarios acuerdos o tratados entre las partes interesadas para que la actividad comercial se llevara a buen término. En estos pactos se debieron concertar una serie de puntos o zonas francas, donde las transacciones, probablemente al amparo de un templo, se harían con garantía total. El papel de los templos como garantes de las transacciones había sido ya establecido por D. Van Berchen $(1967,76)$. Para G. Bunnen (1979, 283), los templos debieron actuar como lugares neutrales situados bajo la protección de un dios, que garantizaba la honestidad de las transacciones. En estos lugares se llevaban los registros y se dirimían los litigios.

En otro aspecto, más relacionado con el tema que se trata y que apoya la hipótesis de una clase dirigente para los grandes poblados de la Alta Andalucía, y más concretamente para Cástulo, se ha de hacer mención a las grandes tumbas halladas en las necrópolis, monumentos funerarios unos de mayor envergadura que otros, que están probando que existía una jerarquía capaz de dominar una mano de obra, de contratar artesanos especializados en la labra de la piedra y en el alzado de las superestructuras. Estos monumentos suelen tener un cierto carácter propagandístico, además del sacro o funerario inherente, que redundaría en la gloria de la estirpe dirigente. Si se atribuye, pues, a una gran mayoría de los restos arquitectónicos de Cástulo la función de elementos funerarios o sacros, se podría determinar que, efectivamente, en la época que trato había en Cástulo espléndidas tumbas principescas o templos. Tales tumbas contribuirian a ayudar a la mitificación o heroización del personaje enterrado, que enaltecería a los descendientes, al hallarse éstos ligados por lazos de sangre a un antepasado a su vez ligado a la divinidad, lo cual, en última instancia, vendría a potenciar la función política.

Grandes sepulturas de cámara se han encontrado en el área castulonense. En la necrópolis del Estacar de Robarinas, durante la campaña de 1976, apareció una gran construcción funeraria, que sus excavadores interpretan como un túmulo escalonado. En la cara oeste del mismo aparecieron numerosos fragmentos escultóricos de bulto redondo, destrozados (BLÁZQUEZ, REMESAL, 1979, 363364). Durante la campaña de excavación de 1982, se aisló, en la misma necrópolis, una estructura rectangular, entre cuyos paramentos se hallaban restos escultóricos, reutilizados como sillares. Este monumento se localizaba sobre un promontorio, visible desde todos los puntos del valle (GARCÍA-GELABERT 1987). En la necrópolis de los Patos, cercana a la de Robarinas, ambas al Oeste de la ciudad de Cástulo y cronológicamente semejantes, como todas las de la zona (fines del siglo $\mathrm{V}$ hasta la primera mitad del siglo IV a. C.), se descubrieron restos de una construcción de forma rectangular, compuesta de sillares bien trabajados (BLÁZQUEZ 1975, 112-117). En la necrópolis de Baños de la Muela, al Este de Cástulo, sus investigadores denominan tumba II a una monumental, al parecer de cámara, perteneciente al tipo $\mathrm{C}$, es decir, túmulos rectangulares de grandes dimensiones, formados por cuatro muros de piedra, con una altura máxima de $0,60 \mathrm{~m}$., y unas dimensiones de $5 \mathrm{~m}$. de ancho y $6 \mathrm{~m}$. de largo (BLÁZZUEZ 1975, 125-132). Muy cerca de esta necrópolis, aproximadamente a $150 \mathrm{~m}$. al Norte, y quizá, aunque algo aislado, perteneciente al mismo ámbito sepulcral, se descubrió un gran monumento funerario, aunque muy destruido y saqueado sistemáticamente, los Higuerones 
(SÁNCHEZ MESEGUER 1979). La base del monumento está realizada con un muro de dos hiladas de piedra trabada sin mortero, con una altura de $0,40 \mathrm{~m}$. y espesor de $0,70 \mathrm{~m}$. La piedra es de mediano tamaño, tosca. Apoyadas sobre este basamento se levantan tres hiladas de adobes, dispuestas al exterior de forma escalonada. La disposición escalonada de los adobes, aproximándose hacie el interior, hizo suponer que pudiera tratarse de los restos de una edificación cubierta con una bóveda por aproximación de hiladas. En el interior se halló una cista vacía, aunque en el área que cubría el cercado fueron recogidos numerosos fragmentos cerámicos de factura indígena e importados. Un poco alejado del túmulo, en un hoyo, hallóse un importante lote de piezas metálicas de procedencia oriental, que probablemente estarían asociadas bien con este monumento, bien con otro cercano. Rodeaba el exterior del túmulo una franja de mosaico, realizado a base de pequeños cantos de río de color blanco y negro grisáceo, formando un dibujo de greca.

En la misma provincia de Jaén, ya fuera del área de Cástulo, se encuentran numerosas tumbas de cámara de gran envergadura; tal es el caso de la tumba de cámara de Castellones de Ceal, la denominada tumba 11. El edificio está construído con losas de piedra arenisca no careadas, unidas con mortero, conformando una planta rectangular. el interior de la edificación fue completamente enlucido, así como la fachada. Se compone este enlucido de una lechada de cal muy pura. El zócalo fue pintado a base de motivos geométricos: semicírculos enlazados, a veces cruzados por líneas en diagonal y con palmas, todo ello con pigmento de almagra, muy abundante en los alrededores de la necrópolis y del poblado, al igual que ocurre en Cástulo. La puerta de acceso es adintelada, formada por un escaño y tres losas de arenisca, tapando la abertura una gran losa. Las losas forman asimismo el techo. Fueron encontrados dos individuos enterrados en sendas urnas, incinerados, acompañados de armas, vasijas y herrajes de caballo (FERNÁNDEZ CHICARRO 1956, 111). El poblado de Castellones de Ceal, al que pertenece la necrópolis, se ha interpretado siempre como un enclave estratégico en función de la vigilancia de una importante ruta comercial que iba desde Cástulo hasta Baza y desde allí a la costa. Y, aunque no se habla expresamente del tipo de comercio, según A. Blanco $(1959,97)$, la vigilancia se centraba en el traslado de la plata a los centros de beneficio y exportación. Según T. Chapa y otros (1984,
223-235), es en el siglo IV a. C. cuando hay una organización diferencial de los asentamientos en conformidad con las características topográficas del terreno, y Castellones pudo responder a esta expansión como controlador de la vía de acceso que desde Murcia y Almería llega al Alto Guadalquivir, e indican, asimismo, que probablemente el contingente humano de Ceal fuese engrosado con población de Toya, llegada tanto como respuesta a esta política de control como para aliviar la posible presión demográfica causada por el desarrollo de Toya.

En la necrópolis de La Guardia se han hallado también cámaras sepulcrales destinadas a personajes importantes (BLANCO 1959, 105-123). La que su excavador denomina tumba I se halla construída con mampostería irregular, aunque cuidada. Se compone la estructura de una cámara rectangular. Anexo al muro noroeste se adosó un banco de 15 $\mathrm{cm}$. de alto y $30 \mathrm{~cm}$. de ancho, en el que se colocaron las ofrendas. La tumba 16 es un recinto cuadrangular, también de mampostería, con cubierta de grandes lajas. En la necrópolis se encontraron numerosos fragmentos de escultura, que pertenecerían a otras sepulturas arruinadas. Como las demás necrópolis tratadas, se fecha aproximadamente hacia los primeros años del siglo IV a. C., prolongándose a lo largo del mismo. El poblado de La Guardia estaba en un lugar eminentemente estratégico, dominando el valle fluvial que se extiende de Nordeste a Sureste, paso obligado desde la Mancha y Despeñaperros hacia las tierras de Granada y costa meriodional. A los pies del poblado, entra dicha ruta en un paso angosto que da al lugar un considerable valor estratégico (BLANCO 1959, 107). En la necrópolis de la Bobadilla, fechada a mediados del siglo VI hasta mediados del siglo siguiente a. C., no obstante haberse localizado una zona pobre de enterramientos, se ha hallado, asimismo, una tumba de cámara de pequeñas dimensiones. La cámara se compone de piedras hincadas. A su cabecera se encuentra un pequeño empedrado que hace las veces de escalón, en el que pudo estar colocado el ajuar. En un ligero hoyo excavado bajo el escalón se encontró un tesorillo, con probabilidad componente del ajuar: un anillo y un juego de pendientes (MALUQUER, PICAZO, RINCÓN, 1981, 15-16). Toya, la antigua Tugia, se encuentra en la ruta de las minas de Cástulo y Sierra Morena y, por tanto, lo mismo por el Sureste que por vía fluvial, el Guadalquivir, debió recibir constantes influencias fenicias y griegas. Según los últimos estudios realizados 
sobre las cerámicas halladas en su necrópolis, ésta pertenece, como las restantes estudiadas, a la cultura ibérica floreciente, es decir, entre la mitad del siglo $\mathrm{V}$, principalmente la segunda mitad, y el siglo IV a. C., al menos su época de apogeo (PEREIRA 1979, 338). Aunque la necrópolis de Toya debió ser de gran amplitud, fue destruída paulatinamente. $\mathrm{Ha}$ llegado a nuestros días un gran sepulcro hipogeo de tres cámaras, perteneciente con toda probabilidad a un gran personaje o a un grupo familiar de alta relevancia dentro de la sociedad ibera de Tugia; es la sepultura cuadrangular. Los muros se construyeron con sillares de tamaño desigual e irregulares, unidos a hueso. El pavimento está constituido por losas, así como el techo, horizontal. El interior se divide en tres naves longitudinales. La central comunica con la única puerta de acceso abierta al Oeste. Las laterales se subdividen, a su vez, en dos ámbitos; el anterior, a modo de antecámara, comunica con la nave central por medio de dos puertas que se abren a ambos lados del comienzo de dicha nave. Por la nave central y laterales corre un banco o escalón, y en los testeros hay excavados varios nichos. Unos y otros debieron tener por finalidad soportar las ofrendas y las urnas y cajas cinerarias. El exterior de la sepultura se cubrió íntegramente de tierra reforzada con piedra (GARCÍA Y BELLIDO 1954, 428-431). Las grandes tumbas de la necrópolis de Baza, adscritas a los tipos $\mathrm{D}_{3} \mathrm{y}_{4}$, según la clasificación de F. Presedo (1982, 303), y denominadas tumbas 155 y 176, respectivamente, son grandes cámaras excavadas en el suelo rocoso del cerro. Contienen importantes ajuares, que sólo pudieron ser costeados por personajes pertenecientes a la más alta oligarquía de la ciudad. Las cámaras suelen estar decoradas con pintura rojo oscuro sobre la cal de las paredes. En la necrópolis de Galera existieron, asimismo, grandes cámaras sepulcrales, que coexistían con las tumbas sencillas, aunque no en los mismo lugares, sino al parecer radicalmente separadas unas de otras, lo que está denotando una extrema diferenciación social. Estas grandes tumbas de cárama se hallan excavadas en la roca de base, conformando una estancia de forma cuadrada o rectangular. Las paredes se dejaban exentas o bien se cubrían por adobes, madera, sillería o mampostería. En muchos casos, incluido el suelo, se enjabelgaba, y a veces se decoraba con motivos geométricos o figurativos en color rojo. Es esencial el color rojo en la mayoría de las sepulturas decoradas de la época. Quizá implicaba un carácter funerario, que realmente tuvo desde época prehistórica, debido, en parte, a una directa alusión a la sangre o al sol en su caída. La cubrición de estas cámaras se llevaba a cabo mediante losas horizontales que se apoyaban en las paredes. Todo el conjunto se cubría por un conglomerado de tierra y piedras, con lo que la necrópolis, en el momento de su funcionamiento, debía dar la impresión de un verdadero campo tumular (GARCÍA Y BELLIDO 1954, 422-428). Entre los enterramientos más sobresalientes figura la sepultura 75, la de mayor envergadura de las excavadas. Consta de una cámara cuadrangular de más de $3 \mathrm{~m}$. de lado. En el centro se colocó un grueso pilar coronado por una especie de zapata con roleos y entrelazados. Un pasillo comunica por el Este la cámara con el exterior. Tanto el pasillo como la cámara se hallaban cubiertos de sillares regulares escuadrados. Excepcionalmente, en el arranque del corredor hay un arco de tres dovelas. El techo, horizontal, estaba constituído por seis grandes losas que se apoyaban en una cornisa que recorre la cámara y en la zapata del pilar central (GARCÍA Y BELLIDO 1954, 426).

Acerca de las tumbas de cámara, con o sin dromos, con o sin túmulo, se han apreciado por numerosos investigadores sus paralelos mediterráneos (entre otros, GARCÍA Y BELLIDO 1935; BLÁZQUEZ 1960: FERNÁNDEZ DE AVILÉS 1942; PELLICER 1969; PEREIRA 1979; ARRIBAS 1967; SCHUBART 1975, y ALMAGRO BASCH 1975).

Soy, asimismo, de la opinión de que estas grandes tumbas de cámara perfectamente pudieron tener su origen inmediatamente anterior en las tumbas de cámara de los asentamientos fenicios y púnicos costeros, teniendo en cuenta el fuerte comerció que se desarrolló entre aquéllos y el hinterland. Concretamente, las tumbas de las necrópolis de Almuñécar (MOLINA, RUIZ, HUERTAS, 1982), Tramayar (SCHUBART, NIEMEYER, 1976) y Villaricos (ALMAGRO GORBEA 1984) debieron ejercer poderosa influencia en este tema. Por su magnitud y grandiosidad serían susceptibles de impresionar a los dirigentes iberos, quienes por su status tratarían directamente con las factorías costeras, e inducirlos a imitar dichas sepulturas para su uso. En cualquier caso, el conocimiento de las mismas pudo ser transmitido, oralmente o a través de dibujos, por los mercaderes orientales que se internaban en la Oretania y Bastetania para comerciar. En ambos casos la vía de difusión cultural son las factorías fenicio-púnicas de la costa. 
La relación económica entre factorías y el hinterland indígena, que en sus comienzos debió poseer únicamente este carácter, con el transcurso del tiempo y los más estrechos contactos, incluso personales y de ideas, debió convertirse en relación económico cultural, con el consiguiente trasvase y asimilación por parte del elemento autóctono $\mathrm{y}$, por qué no, en sentido inverso, de ideas sociales y rituales. Este reflejo podría encontrarse en la adopción por parte de las clases altas de la sociedad ibera de la sepultura de cámara, afín con el desarrollo de la misma, aunque quizá hay que tener en cuenta que esta adopción sólo implicase la superestructura, muy adecuada a la manifestación externa de riqueza de una alta jerarquía dirigente, monopolizadora de los recursos económicos, que fabrica para su última morada un receptáculo digno de su posición social y que, en cambio, se conservase en esencia, aunque con no significativas variantes materiales, el ritual generalizado desde generaciones pasadas y consagrado por el uso, conforme a los preceptos de su religión.

Estas tumbas, pertenecientes a un solo personaje o a un clan familiar, puesto que existen tumbas individuales y colectivas, están indicando una diversificación jerárquica en la sociedad ibérica muy marcada, una idea de jefatura, de liderazgo, que de haber continuado su derarrollo, truncado por el arribo púnico y romano, hubiera desembocado en una fuerte confederación y, más adelante, en Estado.

Indica M. Almagro Gorbea $(1982,252)$ : «las factorías controlan el acceso al mar de las vías que conducen hacia el interior, cruzando toda el área por donde se extienden las cámaras hipogeas ibéricas, lo que evidencia que esas vías de comunicación han actuado como vías de difusión cultural, afectando a toda un área geográfica que se debe considerar, en consecuencia, como hinterland cultural de las colonias y factorías de la costa y, por lógica extensión, como hinterland económico de las mismas». Buena prueba de ello es que las grandes tumbas de cámara se encuentran en las necrópolis de los poblados, más instaladas en las principales vías de comunicación y, en ocasiones, en los lugares estratégicos de control de caminos, digamos, en términos de lenguaje actual, como monumentos propagandísticos de la estirpe del difunto, dando, por supuesto, además, el significado propio religioso.

Las grandes tumbas de mampostería que se hallan, como se ha indicado, en los poblados ibéricos del interior, Galera y Baza, en Granada; La Guar- dia, Toya, Castellones de Ceal, la Bobadilla, en Jaén, señalan una ruta muy específica, en la que las influencias se han dejado sentir de manera palpable en todos los aspectos de la vida cotidiana, económica, cultural y religiosa de sus poblaciones. Por ello no es de extrañar que estas tumbas de cámara proliferen en la zona de Cástulo, donde las grandes necrópolis, adscritas a la época de esplendor ibérico, son muy abundantes, y que constituyan un rasgo tipo de la eclosión de las jefaturas.

En el contenido de las necrópolis de Cástulo, y más concretamente en la del Estacar de Robarinas, hay al menos un enterramiento, el denominado IX -sólo se excavaron 34 tumbas y se calcula que éstas podrían constituir un tercio del total-, que claramente pertenece a un mercenario procedente de las tribus de la Meseta. En el ajuar que acompaña a los restos incinerados del individuo, hay objetos de uso personal, armas, huesos de animales, arreos de caballo, cerámica griega, indígena decorada y lisa y gris, distribuidos en varias zonas de ofrendas. Merece destacar, en apoyo de la hipótesis esbozada, que entre las armas hay un gran broche de cinturán de bronce - placas activa y pasiva - decorada la activa con damasquinado de hilo de plata que compone decoración vegetal estilizada, volutas, entrelazos y espirales; una espada de hierro con antenas atrofiadas, cuya empuñadura, asimismo, se decoró por damasquinado con hilo de plata limitado por otros de cobre; el diseño es muy primitivo y aún así participa del mismo concepto decorativo que el broche; una vaina, probablemente de la espada, compuesta de varias varillas, un travesaño peraltado en forma de puente para sujetar las anillas y parte de la caja donde se alojaba un pequeño cuchillo. Esta vaina está decorada con la misma técnica de damasquinado a base de líneas de embutido de plata que delimitan pequeños campos cuadrados, en cuyo interior se encierran círculos. Completa el conjunto un cuchillito afalcatado, que pudo corresponder al que solían portar en el cajetín de la vaina (GARCÍAGELABERT 1987). Este armamento es característico de un soldado procedente de la Meseta. Los broches del tipo del de Robarinas fueron muy apreciados por los guerreros de aquella región. Se encuentran en la mayoría de los ajuares de las necrópolis correspondientes a los grandes castros del centro de la segunda Edad del Hierro, por ejemplo en la Osera, Chamartín de la Sierra; las Cogotas, Cardeñosa —ambos en Ávila-; Altillo de Cerropozo; Atienza, en Guadalaja; Arcóbriga, Monreal de Ariza, en 
Zaragoza; Uxama, Gormaz y Quintana de Gormaz, en Soria. La espada, su vaina y el cuchillito pertenecen al tipo de armamento predominante en el mundo de la Meseta en tales momentos, en el ambiente de la cultura de Cogotas. Aunque, sobre todo la espada y su vaina, se hallan en la mayoría de los ajuares funerarios de las citadas necrópolis y de otras no nombradas para no hacer tediosa la enumeración, es en la de la Osera de Charmartín de la Sierra donde se conocen los ejemplares más semejantes a los de Robarinas (CABRÉ y otros 1950, 175).

La superestructura de la tumba que pudo corresponder a un mercenario, en Robarinas, y el contenido del ajuar, denotan una persona de cierta posición social, aunque no perteneciente a la clase jerárquicamente más alta, quizá un jefe de tropa mercenaria. No parece probable que estas armas fuesen adquiridas mediante trueque a los mercaderes del interior, cori los que evidentemente mantenían relaciones los pobladores de Cástulo; antes bien, responden a un equipo, muy homogéneo, de un individuo con una concepción estética y utilitaria que se aparta de la del resto de los guerreros enterrados en Robarinas y, en cambio, se acerca al mundo de la Meseta. Pudo, por consiguiente, tratarse efectivamente de un guerrero mercenario, de los que abundaban en el Sur a las órdenes de los jefes de poblado o tribu. La presencia de estos mercenarios en Cástulo indica un grado de civilización y de riqueza y una organización política capaz de canalizar sus actividades hacia el fin deseado de protección de la clase que los alista. Se ha indicado ya que los acuerdos comerciales parecían tener un carácter marcadamente político y que únicamente los poderosos podían asegurar el cumplimiento de su contenido. De ahí que la organización comercial, desarrollada mediante cauces político-administrativos, estuviera respaldada por la fuerza militar. Estaba engrosada por tropas mercenarias si la sociedad que la requería no disponía de los efectivos necesarios. Se llevaban a cabo levas entre los pueblos celtíberos y lusitanos principalmente, los cuales, acuciados por la falta de tierras, se ofrecían a ser reclutados.

La adopción o presencia de mercenarios es señal del alto nivel económico alcanzado por la sociedad que los recluta, e indicio de que se trata de una sociedad con un patrón socioeconómico complejo, muy alejado de los estadios políticos que co- rresponden a pueblos jerárquicamente poco diferenciados.

Livio $(34,17)$ cita como mercenarios de los Turdetanos a los Celtíberos y como tal figuran en número de diez mil (año 195 a.C.) en la gran rebelión de los Turdetanos, encabezada por Budar y Besadines, contra los romanos. Celtíberos e iberos fueron mercenarios de cartagineses y romanos, basculando de un campo a otro según el estipendio ofrecido.

Mercenarios celtíberos fueron los primeros que admitieron los romanos en su ejército (LIVIO, 24, $49,7)$. Son mencionados asimismo como mercenarios Istolacio e Indortes (LIVIO, 34, 19). Sobre ellos incide Diodoro $(25,10)$ cuando alude a las luchas de Aníbal contra los iberos y tartesios y contra Istolacio. Otros nombres de caudillos que militan a las órdenes de cartagineses contra romanos en el Sur, en 214-212 a. C. (LIVIO, 24, 41) son, como Istolacio e Indortes, de origen indoeuropeo: Moenicoeptus y Vismarus, a los que Livio llama reguli gallorum $(24,41)$. La columna vertebral del ejército cartaginés estaba compuesta de Lusitanos y Celtíberos (GARCÍA Y BELLIDO 1975, 647). Nuevamente Livio hace mención a los mercenarios celtíberos al indicar que éstos por el mismo dinero que en el ejército cartaginés sirven en el romano $(24,29,7)$. A uno de los jefes celtíberos, Bellígenes, le regalaron tierras los romanos para recompensar su traición a los púnicos (LIVIO, 26, 21, 13).

Estos mercenarios del centro peninsular, por su belicosidad y extraordinaria movilidad, eran sumamente apreciados por los ejércitos púnico y romano, así como por los pueblos del Mediodía peninsular. Generalmente eran reclutados entre aquéllos cuyas condiciones sociales y económicas en sus propias tribus eran penosas. Por otra parte, y como indica A. García y Bellido (1975, 649-670), el estado de rivalidad y fraccionamiento de los pueblos peninsulares, hecho remarcado por Estrabón $(3,4,5)$, hacía que estas tropas indígenas fueran relativamente seguras.

Se ocuparon también de los mercenarios ibéricos, entre otros, Polibio $(1,17 ; 1,67 ; 14,7 ; 14,8$; 114, 2-3; 114, 4); Plutarco (Fab. Max, 7; Catón, 10); Tucídides $(6,90)$ y Diodoro $(15,70 ; 16,73,3)$.

Como ejemplo gráfico de la presencia del elemento humano del centro de la Península en el Sur, se ha observado en el análisis de la escultura de Obulco (BLÁZQUEZ-GONZÁLEZ NAVARRETE 
1985, 61-69) que gran parte del armamento que portan los guerreros representados se corresponde con las armas usadas por las tribus de la Meseta. También en los exvotos de los santuarios ibéricos hay figurillas portando armas de procedencia meseteña (GARCÍA Y BELLIDO 1954; figs. 326, 333, 335, 338 y 342). Y en los relieves de Osuna (GARCÍA Y BELLIDO 1954; figs. 481, 482 y 487).

En las necrópolis de Cástulo y lo mismo en las restantes de la Alta Andalucía que se han tratado, se observa un trato diferencial a los muertos, lo que manifiesta la desigualdad evidente que existía entre grupos de personas en relación con el resto de la sociedad (SANOJA-VARGAS 1985). Dicha desigualdad podría estar reflejando las distinciones que existieron entre unos y otros grupos sociales (HATCH 1985). De entre las 34 tumbas excavadas, unas y otras fueron, en su tiempo, tratadas de manera diferente, tanto en su superestructura como en la composición del ajuar - por el contrario, la preparación del receptáculo, que pudo obedecer a un determinado rito, revestido de arcilla pura, es idéntica en todas-. En cuanto a las superestructuras, unas son amplias cámaras construídas con piedra de sillería, que pudieron llevar adosados, al exterior, grupos escultóricos, a juzgar por los restos que se han hallado; otras son túmulos cuadrangulares, hechos a base de piedra cuidada, sobre todo en las esquinas, y rodeados de una cenefa de cantos rodados, formando ésta diseños geométricos; otras son estructuras circulares, rectangulares o cuadrangulares de piedra menuda; otras son cistas; otras sepulturas carecen de superestructura, los restos se cubren con una capa de arcilla y piedra, y otras, finalmente, son sencillas urnas calzadas con piedras de diferentes tamaño.

Los ajuares, asimismo, son distintos y acusan el status social de la persona enterrada. Las sepulturas de mayor envergadura en cuanto a la superestructura contienen ricos ajuares de armamento, vasos griegos, ungüentarios, collares de pasta vítrea, objetos de uso personal como sortijas, fíbulas, pendientes, broches. En las de estructura tumular rodeadas de cenefa de cantos rodados, el ajuar no está integrado por armas, pero sí por numerosos vasos griegos. En cambio, aquellas cuya estructura es circular, rectangular o cuadrangular, de piedra menu$\mathrm{da}$, continen abundante armamento y carecen de vasos griegos. Éstos son sustituidas por vasos de barniz rojo. Las que sólo presentan un simple hoyo excavado en la tierra y los restos son cubiertos por arcilla y piedra, y lo mismo las cistas aisladas (exis- ten cistas en el interior de los grandes monumentos funerarios, que no entran en esta relación), apenas tienen como ajuar escasos objetos de uso personal, a veces únicamente las bases retocadas de vasos cerámicos, en particular grises. Las urnas calzadas con piedra carecen de ajuar.

A tener en cuenta es el destino de muchos de los objetos producto de comercio, cuales son vasos griegos, ungüentarios, collares de cuentas de pasta vítrea, conchas marinas, cajas de madera tallada. $\mathrm{Su}$ enterramiento con las cenizas de los individuos era también una forma de que circularan, mediante su consumo ritual. De esta forma se creaba una demanda constante de bienes suntuarios que mantenían en continua circulación las redes de intercambio que funcionaban a nivel de sociedad. Este sistema pudo constituir una forma de mantener la integración política que fundamentaba la sociedad de jefatura, al menos en parte, puesto que numerosos objetos suntuarios se dedicarían, como es lógico, al mundo de los vivos.

En Cástulo, por falta de excavaciones sistemáticas en el área de poblamiento ibérica, no se han podido localizar edificios públicos, aunque a juzgar por los restos arquitectónicos recogidos en superficie, como capiteles, dinteles y frisos labrados, parece que pudo haberlos. Estos edificios, si se encontrasen, apoyarían la hipótesis de una jefatura dirigente, puesto que los mismos lógicamente serían levantados con la fuerza de trabajo organizada y constituirían una forma de realzar la estirpe de la clase dominante, más que una inversión social de la comunidad en el entorno que habita.

Recapitulando, se podría afirmar, con Castaño Uribe (1985), que «la metodología propia de la arqueología procesual de las últimas décadas ha superado numerosos obstáculos al observar una sociedad, no como un conjunto de rasgos independientes, sino como un sisitema evolutivo compuesto por una red de procesos internos de desarrollo estrechamente interactuantes... Se ha llegado a un relativo consenso en cuanto a la determinación de niveles universales de organización sociopolítica y a sus elementos o complejos más característicos, pero la denominación misma y los rasgos de cada nivel dependen de las esferas o instituciones que se tomen como punto de referencia». En el caso de la sociedad de Cástulo, estos puntos de referencia son muy limitados, falta que el poblado sea excavado y las necrópolis lo han sido parcialmente. No obstante, esencialmente a través de ellas, del análisis del medio am- 
biente y de la interpretación de los textos clásicos, insuficientes cuando se refieren a las sociedades autóctonas, se logra conocer, al menos en parte, las características de la sociedad, la organización sociopolítica y los procesos de transformación y de comercio, aunque lógicamente con unas limitaciones que implican que pretender extraer del proceso de los datos recuperados conclusiones definitivas, lo que no se ha pretendido en ningún momento, resulte aventurado.

En Cástulo existían especialistas desligados de la producción directa de alimentos, cuyo papel estaría relacionado con la centralización y redistribución de excedentes comunales. Esto lleva implícita la disgregación de la sociedad igualitaria de autoconsumo. La legitimación de las formas sociales estratificadas se hace mediante una cierta organización de la fuerza de trabajo. Ello compete al jefe. Esta organización se puede realizar a través de una diferenciación del mismo en sectores primarios (producción directa), secundarios (transformación de materias primas) o terciarios (distribución de bienes manufacturados o de materias primas) (SANOJA-VARGAS 1985).

Un alto grado de producción minera, como la que parece existió en Cástulo, si atendemos a las fuentes, pudo haber potenciado, como creo que así fue, el predominio político de Cástulo sobre los poblados colindantes, como receptor de la materia prima y como centro de distribución del producto. Desde este punto de vista, se dinamiza la estructura política, a cuyo frente se encontraría un jefe supremo (paramount chief), conforme a la terminología de Frankenstein y Rowlands $(1978,84-85)$. La redistribución, según Service $(1971,94)$, parece estar íntimamente aliada con el surgimiento y perpetuación del liderazgo. Y en la medida en que la redistribución esté extendida y formalizada, puede estarlo también el poder. La existencia de los centros redistributivos, como evidentemente fue Cástulo, está indicado, según Service $(1971,222)$, una sociedad de jefatura, la cual tiene la organización adecuada para extender ampliamente el sistema redistributivo y de intercambio. Estas sociedades, al ser económica y militarmente más poderosas, si se comparan con las sociedades igualitarias de los pueblos del entorno - se supone la ciudad de Cástulo como un núcleo semiurbano o urbano-, transformaron y aglutinaron a éstos, lo que revertiría a la desaparición o asimilación de las jefaturas locales en lo que denominan Frankenstein y Rowlands vassal chief o jefes vasallos. Este hecho lo pone de relieve M. Almagro Gorbea $(1977,504)$ al tratar de la primitiva cultura ibérica en el valle del Guadalquivir.

Existen pruebas materiales de una sociedad estratificada o jerarquizada en la radical tipología de enterramientos y en los componentes de los ajuares de los mismos. Si se asume esta estratificación, cabe pensar que las grandes tumbas tumulares, muchas de las cuales se hallaban ornadas con esculturas de animales guardianes, especialmente, corresponderían a los jefes supremos. A estos jefes competirían: el concierto de los pactos con los comerciantes orientales para salvaguardar el comercio; el promover las levas para reclutar mercenarios que engrosaran la fuerza militar destinada al control de las zonas clave de paso y de las minas; controlar el acceso a la producción y al consumo de bienes; control de la redistribución; encauzar la fuerza humana destinada a la construcción de edificios públicos y sacros, que evidenciarían el prestigio y el poder del mismo y de su estirpe.

En los textos clásicos se nombra al alguno de estos jefes, o al menos personajes importantes, a los que se les denomina príncipes, reyezuelos, reyes, caudillos, jefes, hecho que no es significativo a los efectos de esta exposición. Livio cita a Amúsico, príncipe de los Ausetanos $(21,61) ;$ Mandonio e In$d i b i l$, reyezuelos de los Ilergetas $(22,61)$-también Polibio $(10,18,3)-$; Chalbo, noble jefe de los Tartesios $(23,26)$; Alucio, joven príncipe celtíbero $(26$, 50) —también Dión Cassio, Fr. 57, 42 (Boiss. I. 243)-; Colchas, rey de veintiocho ciudades (28.10; $33,21.6)$ y Luxinio, de dos $(33,21.6)$; Attenes, rey de los Turdetanos $(28,12,15)$; Cerdubelo, el personaje castulonense que aconsejó la rendición de la ciudad a los romanos $(28,19)$; Corbis y Orsua, primos que luchaban entre sí por el principado de Ibes $(28,21)$; Bilistages, rey de los Ilergetes $(34,11) ; \mathrm{Hi}$ lerno, rey celtíbero $(34,55,6)$; Corribilon, reyezuelo de Licabro $(35,22,5)$; Thurro, reyezuelo celtíbero (49). Polibio cita a Edecón, rey de los Edetanos $(10,34)$; Macrobio, a Theron, reyezuelo contestano (St. I. 20, 12); Diodoro, a Istolacio, general de los Celtas, y al rey Orisson $(25.10 ; 25.12)$.

La sociedad de jefatura para los pueblos iberos ha sido recientemente propugnada por varios investigadores, entre los que cabe citar a A. Domínguez Monedero (1984, 153), quien postula este tipo de sociedad para la sociedad contestana en una época similar a la que se trata para Cástulo. R. López Domech $(1984,142-43)$ esboza la misma hipótesis para 
los Oretanos. Escribe: «los Oretanos, a la llegada de los cartagineses a esta zona, estaban en un estadio intermedio entre la tribu y la organización social superior, la jefatura, que responde al paso de una economía cerrada y comunal a una incipiente economía más abierta. El jefe, ya que no se puede hablar de rey...»». C. González Wagner apunta hacia la misma hipótesis que se esboza, en este caso para las sociedades del mediodía peninsular, involucradas en el comercio exterior; indica que se pasaría de unas sociedades igualitarias o incipientemente jerarquizadas a formas de organización social más centralizadas y con una jerarquía mayor, como consecuencia de la especialización económica (1983, 10-13). Por último, J. Alvar (1986), cuando escribe que el mundo tartésico se descompone a fines del siglo VI a. C. en un mosaico de reino de taifas, piensa que sería más apropiado hablar de una descomposición bajo la forma de jefaturas o chiefdoms de carácter menor, éstas dinamizadas por un influjo foráneo: el que tiene lugar como consecuencia del comercio oriental.

Se ha querido dar a este estudio el carácter de planteamiento del problema de la evolución política de las sociedades ibéricas en su período de esplendor, tomando como punto de referencia la sociedad de Cástulo. Queda, pues, el tema abierto a discusión y susceptible de retoques y modificaciones posteriores, si hubiere lugar.

\section{BIBLIOGRAFÍA}

ADAMS, R. M. 1966: The evolution of urban society: Early Mesopotamia and Prehistoric Mexico. Aldine, Chicago.

ADAMS, R. N. 1975: Energy and structure: A theory of social power, Univeristy of Texas Press, Austin.

ALMAGRO BASCH, M. 1975: «Las raices del arte ibérico». PLAV 11, 251-279.

ALMAGRO GORBEA, M. 1977: El Bronce final y el período orientalizante en Extremadura. BPH XIV, Madrid.

- 1982: «Tumbas de cámara y cajas funerarias ibérica. Su interpretación sociocultural y la delimitación del área cultural ibérica de los bastetanos», Homenaje a C. Fernández Chicarro, 250-257, Madrid.

ALMAGRO GORBEA, M. J. 1984: «La necrópolis de Baria (Almería). Campañas de 1975-78». EAE, 129.

ALVAR, J. 1980: «El comercio del estaño atlántico en el período orientalizante», $M H A, 45$ ss.

- 1981: La navegación prerromana en la Península Ibérica: colonizadores $e$ indigenas, Madrid.
- 1986: «Theron, rex Hispaniae Citerioris (Macr., St. I. 20.12)», Gerión 4; 161-175.

ARRIBAS, A. 1967: «La necrópolis bastitana del Mirador de Rolando (Granada), Pyrenae 3, 67-105.

BELL, R.; EDWARD, D. V., y WAGNER, R. H. (eds.). 1969: Political Power: a reader in theory and research, Free Press, New York.

BLANCO, A. 1959: «Excavaciones arqueológicas en la provincia de Jaén», BIEG 22, 89-125.

BLÁZQUEZ, J. M. 1960: «La cámara sepulcral de Toya y sus paralelos etruscos», Oretania 5, 233-244.

- 1975: «La necrópolis ibérica de los Patos», en Cástulo, I. Acta Arq. Hispánica 8, 41-121.

- 1975: «La necrópolis de Baños de la Muela», en Cástulo I, 123-218.

BLÁZQUEZ, J. M., y GONZÁLEZ NAVARRETE, J. 1985: "The phokaian sculpture of Obulco in Southern Spain», $A J A$ 89, 61-69.

BLÁZQUEZ, J. M., y REMESA J. 1979: «La necrópolis del Estacar de Robarinas", en Cástulo II, EAE 105, 347-404.

BUNNEN, G. 1979: L'expansion phenicienne en Méditerranée, Bruxelles.

CABRÉ, J.; CABRÉ, M. E., y MOLINERO, A. 1950: «El castro y la necrópolis del hierro céltico de Chamartín de la Sierra (Ávila)», Acta Arq. Hispánica 5.

CARNEIRO, R. L. 1981: «The chiefdom: precursor of the state», en The transition to statehood in the New World (Jones-Kautz, eds.), 37-79, Cambridge University Press, Cambridge.

CASTAÑO URIBE, C. 1987: «La vivienda y el enterramiento como unidades de interpretación de los casos de transición del modelo de cacicazgo», 45th International Congress of Americanists, Bogotá. Session entitled «Archaeological Investigation and chiefdom in America» (1985), en R. Drennan y C. Castaño (eds.), Chiefdoms in the America, University Press of America Inc., London-Toronto.

CLAESSEN, H., y SKALNIK, P. M. (eds.). 1978: The early state, Mouton, The Hague.

COHEN, R., y SERVICE, E. R. (eds.). 1978: Origins of the state: the anthropology of political evolution, Institute for the Study of Human Issues, Philadelphia.

CHAPA, T.; FERNÁNDEZ, M.; PEREIRA, J., y RUIZ, A. 1984: «Análisis económico y territorial de los Castellones de Ceal (Jaén)», Coloquio sobre distribución y relaciones entre asentamientos 4, 223-235, Teruel.

DOMINGUEZ MONEDERO, A. 1984: «La escultura animalística contestana como exponente del proceso de helenización del territorio", Coloquio sobre distribución y relaciones entre asentamientos 4, 141-160, Teruel.

EARLE, T., y ERICSON, J. E. (eds.). 1977: Exchange systems in Prehistory, Academic Press, New York.

FERNÁNDEZ DE AVILÉS, A. 1942: «La cámara de Toya», AEspA 49, 344 ss.

FERNÁNDEZ CHICARRO, C. 1956: «Prospección arqueológica en los términos de Hinojares y La Guardia (Jaén)», BIEG 7, 101-120.

FINLEY, M. I. 1974: La economía en la Antigüedad, México.

FRANKESTEIN, S., y ROWLANDS, M. J. 1978: «The internal structure and regional context of Early Iron Age Society in South Western Germany), Institute of Archeology Bulletin, 15, 73-112.

FRIED, M. H. 1967: The evolution of political society: an essay in political Anthropology, Random House, New York.

FRIEDMAN, J., y ROWLANDS, M. J. (eds.). 1978: The evolution of social systems, University of Pittsburg Press, Pittsburg. 
GARCÍA Y BELLIDO, A. 1935: «La cámara de Toya y sus paralelos mediterráneos», Actas y Memorias de la SEAEP, $\mathrm{XV}$.

- 1954: «Arte ibérico», en Historia de España. España Prerromana I, 3. Madrid.

- 1975: «Los mercenarios españoles en Cerdeña, Sicilia, Grecia, Italia y Norte de África», en Historia de España. España Protohistórica I, 2. Madrid.

GARCÍA-GELABERT, M. P. 1987: La necrópolis del Estacar de Robarinas: Ritos y creencias. Tesis Doctoral (ms.). Madrid.

GONZÁLEZ ẄAGNER, C. 1983: «Aproximación al proceso histórico de Tartessos», AEspA 56, 3-36.

HAAS, J. 1979: The evolution of the Prehistoric State: Toward an archaeological analysis of political organization, $\mathrm{PH}$. D. dissertation, Columbia University. New York.

HATCH, J. W. 1987: «Mortuary indicators of organizational variability among the southeastern U. S. chiefdoms», 45th International Congress of Americanists, Bogotá. Session entitled «Archaeological Investigation and chiefdom in America» (1985), en R. Drennan y C. Castaño (eds.), Chiefdoms in the America, University Press of America Inc., London-Toronto.

HIGUERAS, A. 1961: El Alto Guadalquivir. Estudio Geográfico. IEG. Zaragoza.

JONES, G., y KAUTS, R. (eds). 1981: «Issues in the study of New World state formation», en The transition to statehood in the New World (Jones-Kautz, eds.), 3-34. Cambridge University Press, Cambridge.

KORNS, N. 1978: Human evolution. New York.

LANESKI, G. E. 1966: Power and privilege: a theory of social stratification. New York.

LÓPEZ DOMECH, R. 1984: «Los vasos áticos del siglo IV a. C.; elemento de interacción comercial en la región de Albacete», Congreso de Historia de Albacete I, 139-143. Albacete.

MALUQUER, J.; PICAZO, M., y DEL RINCÓN, M. A. 1981: «La necrópolis ibérica de la Bobadilla (Jaén)», PIP IV, 152. Barcelona.

MOLINA, F.; RUIZ, A., y HUERTAS, C. 1982: Almuñécar en la antigüedad. La necrópolis fenicio-púnica de Puente de Noy. Granada.

OBERG, K. 1955: «Types of social structure among the lowland tribes of South and Central Americas, American Anthropologist 57, 472-487.

PELLICER, M. 1969: «Las primeras cerámicas a torno pintadas andaluzas y sus problemas», en Tartesos y sus problemas. V Sympósium Internacional de Prehistoria Peninsular, 291-310. Barcelona.

PEREIRA, J. 1979: «La cerámica ibérica procedente de Toya (Peal de Becerro, Jaén)», en el Museo Arqueológico Nacional, Trabajos de Prehistoria 36, 289-347.
POLANYI, K. 1976: «La economía como actividad institucionalizada», en Comercio y mercado en los imperios antiguos (Polanyi, Arensberg-Pearson eds.), 289-316. Barcelona.

PRESEDO, F. 1982: «La necrópolis de Baza», EAE 119.

REDMAN, C. L. 1978: The rise of civilization. San Francisco.

RUIZ, A., y MOLINOS, M. 1984: «Elementos para un estudio del patrón de asentamiento en las campiñas del Alto Guadalquivir durante el horizonte ibérico pleno (un caso de sociedad agrícola con Estado)», Coloquio sobre distribución $y$ relaciones entre asentamientos $4,187-206$. Teruel.

RUIZ, A.; NOCETE, F., y SÁNCHEZ, M. 1986: La Edad del Cobre y la argarización en tierras giennenses, Homenaje a Luis Siret (1984), 271-286, Cuevas de Almanzora.

SAHLINS, M. D., y SERVICE, E. R. (eds.). 1960: Evolution of culture. University of Michigan Press, Ann Arbor.

SÁNCHEZ MESEGUER, J. R. 1979: «Los Higuerones», en Cástulo II. EAE 105, 416-429.

SANOJA, M., y VARGAS, I. 1987: «La sociedad cacical del Valle de Quibor (Edo. Lara, Venezuela)», 45th International Congress of Americanists, Bogotá. Session entitled «Archaeological investigation and chiefdom in America» (1985), en R. Drennan y C. Castaño (eds.), Chiefdoms in the America, University Press of America Inc., LondonToronto.

SCHUBART, H. 1975: «Formación de colonias fenicias en la costa mediterrénea», PLAV 11, 199-206.

SCHUBART, H., y NIEMEYER, H. G. 1976: «Trayamar. Los hipogeos fenicios y el asentamiento en la desembocadura del río Algarrobon, EAE 90.

SERVICE, E. R. 1962: Primitive Social Organization. An evolutionary perspective (2. ${ }^{\mathrm{a}}$ ed., 1971), New York.

SPENCER, Ch. S. 1987: «Rothinking the chiefdom», 45th Internacional Congress of Americanists, Bogotá. Session entitled «Archaeological Investigation and chiefdom in America» (1985), en R. Drennan y C. Castaño (eds.), Chiefdoms in the America, University Press of America Inc., London-Toronto.

STEWARD, J. H. (ed.). 1948: Handbook of South American Indians, 4: The Circum-Caribbean Tribes. Smithsonian Institution. Bureau of American Ethnology Bulletin 143, Washington.

STEWARD, J. H., y FARON, L. C. 1959: Native peoples of South America. New York.

TRIMBORN, H. 1949: Señorío y barbarie en el Valle de Cauca. Instituto «Gonzalo Fernández de Oviedo», CSIC, Madrid.

VAN BERCHEN, D. 1967: «Santuaires d'Hercules Melkart. Contribution a l'étude de l'expansion phenicienne en Méditerranée», Siria XLIV. 